\title{
Análise do tempo e dimensão epistemológica do saber: limite de uma função real ${ }^{1}$
}

Analysis of the time and epistemological dimension of knowledge: the limit of a real function

\author{
Teodora Pinheiro Figueroa ${ }^{2}$ \\ Saddo Ag Almouloud ${ }^{3}$
}

\section{Resumo}

Este artigo apresenta o resultado de parte de uma pesquisa de pós-doutorado que se refere a construção de uma linha do tempo a respeito das primeiras ideias do objeto matemático Limites de Funções de uma Variável Real, do século $V$ a.C. com os paradoxos de Zenão até o século XIX d.C. com Louis-Augustin Cauchy (1789-1857) e Karl Weierstrass (1815-1897), cujo período envolve um estágio inicial, intermediário e formal do conceito. A partir destes relatos, o objetivo específico é construir um mapa epistemológico deste saber, englobando aspectos históricos e filosóficos, a fim de responder algumas questões referentes a dimensão epistemológica: Qual a gênese do saber? Quais os conhecimentos envolvidos na construção deste saber? Acredita-se que as respostas a essas questões serão de fundamental importância tanto para o pesquisador em didática da matemática, como para o professor de matemática.

Palavras chave: limites; mapa epistemológico; história da matemática.

\section{Abstract}

This paper presents the result of part of a postdoctoral research on the construction of a timeline on the first ideas of mathematical object Limits of a Variable Real from the fifthcentury until the nineteenth century with Louis-Augustin Cauchy (1789-1857) and Karl Weierstrass (1815-1897), whose period involves an initial, intermediate, and formal stage of the concept. From these reports, the specific objective is to construct an epistemological map of this knowledge, encompassing historical and philosophical aspects, to answer some questions concerning the epistemological dimension: What is the genesis of knowledge? What knowledge is involved in building this knowledge? It is believed that the answers to these questions will be of fundamental importance both for the researcher in mathematics didactics and for the mathematics teacher.

Keywords: limits, epistemological map, historical aspects, history of mathematics.

\footnotetext{
${ }^{1}$ Este artigo é um dos resultados da pesquisa relacionada ao estágio de Pós-doutorado em Educação Matemática que vem sendo realizado até este momento pela primeira autora no Programa de Estudos Pósgraduados em Educação Matemática da PUC/SP.

2 Universidade Tecnológica Federal do Paraná | teodora.pinheiro@gmail.com

${ }^{3}$ Pontifícia Universidade Católica de São Paulo | saddoag@gmail.com
} 


\section{Introdução}

Os primeiros registros em matemática surgiram a partir do desenvolvimento do homem e de questionamentos em relação a sua própria existência e subsistência na terra. Em diversos aspectos da história da humanidade as reflexões filosóficas contribuíram para o exercício da mente e do intelecto, pois incluem um processo de investigação, raciocínio e possíveis julgamentos que levam consequentemente a obtenção de conhecimentos que estão associados a um determinado saber, além de contribuírem na determinação da gênese deste saber.

Sendo assim, existe um universo do saber de cada objeto matemático do ponto de vista histórico e filosófico e, o conhecimento deste universo enriquece a formação do professor de matemática, não apenas no sentido de recursos para a transposição didática, mas principalmente no entendimento do que é o fazer matemático. Esse fazer matemático se refere neste trabalho ao levantamento de hipóteses, de criação de estratégias, de argumentação, de capacidade de representação de um saber específico.

Segundo D'Ambrósio:

Ninguém poderá contestar que o professor de matemática deve ter conhecimento de sua disciplina. Mas a transmissão desse conhecimento por meio do ensino, no presente, depende de sua compreensão de como esse conhecimento se originou e quais as principais motivações para o seu desenvolvimento, o que se aprende do passado, e quais as razões de sua presença nos currículos escolares, o que se justifica pela visão de futuro. Esse encadeamento é um dos principais objetivos da História e Filosofia da Matemática. (D'AMBRÓSIO, 2011)

Dessa forma, a ideia geral deste trabalho é apresentar a construção de uma linha do tempo a respeito das primeiras ideias do objeto matemático Limites de Funções de uma Variável Real, do século V a.C. com os paradoxos de Zenão até o século XIX d.C com LouisAugustin Cauchy (1789-1857) e Karl Weierstrass (1815-1897), cujo período envolve um estágio que classificamos como inicial, intermediário e formal do conceito. A partir destes relatos, o objetivo específico é construir um mapa epistemológico deste saber, englobando aspectos históricos e filosóficos, a fim de responder algumas questões referentes a dimensão epistemológica: Qual a gênese do saber? Quais os conhecimentos envolvidos na construção deste saber? Acredita-se que as respostas a essas questões serão de fundamental importância tanto para o pesquisador em didática da matemática, como para o professor de matemática.

\section{Linha do tempo: Aspectos Filosóficos, Matemáticos e Históricos}

Primeiramente realizou-se a construção de uma linha do tempo a respeito das primeiras noções do objeto matemático Limites de Funções de uma Variável Real do século V a.C. até o século XIX d.C, conforme a Figura 1. 


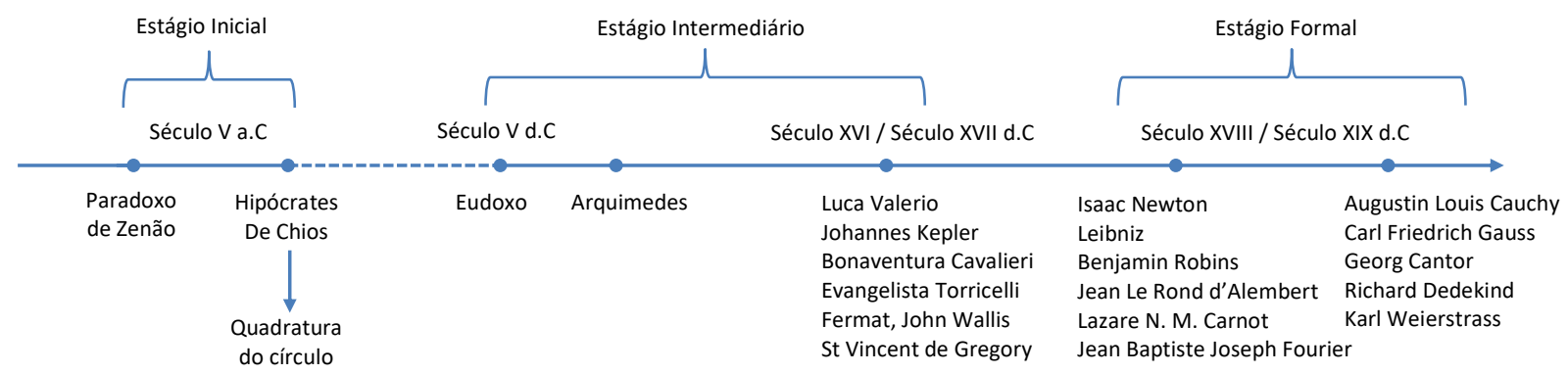

Figura 1: Análise do tempo - Limites

Neste caso, as análises e reflexões deste trabalho de pesquisa serão apresentados em três etapas, conforme a Figura 1: Estágio Inicial, Estágio Intermediário e Estágio Formal.

Acredita-se que o estudo sobre os períodos que envolvem cada Estágio contribua para a construção de um mapa epistemológico do saber em questão e, favoreça subsídios para responder as questões: Qual a gênese do saber? Quais os conhecimentos envolvidos na construção deste saber?

\section{Estágio Inicial}

O estágio inicial é caracterizado neste trabalho primeiramente por um relato do pensamento matemático das primeiras civilizações: egípcia e babilônica, as questões filosóficas a respeito de conceitos como o movimento, o indivisível, os infinitesimais e as primeiras reflexões sobre o infinito, os quais provocaram evoluções no pensamento matemático da época que impactaram diretamente na definição formal atual de Limites de Funções de uma Variável Real.

Sendo assim, primeiramente apresentamos um esquema (Figura 2) com as ideias reconhecidas como fundamentais para a compreensão da definição formal de Limites de uma Função de uma Variável Real. Essas ideias foram evidenciadas como importantes para a compreensão dos alunos da definição formal de Limites, segundo os resultados de pesquisas de Tall (1980), Zuchi (2005) e Lira (2008).

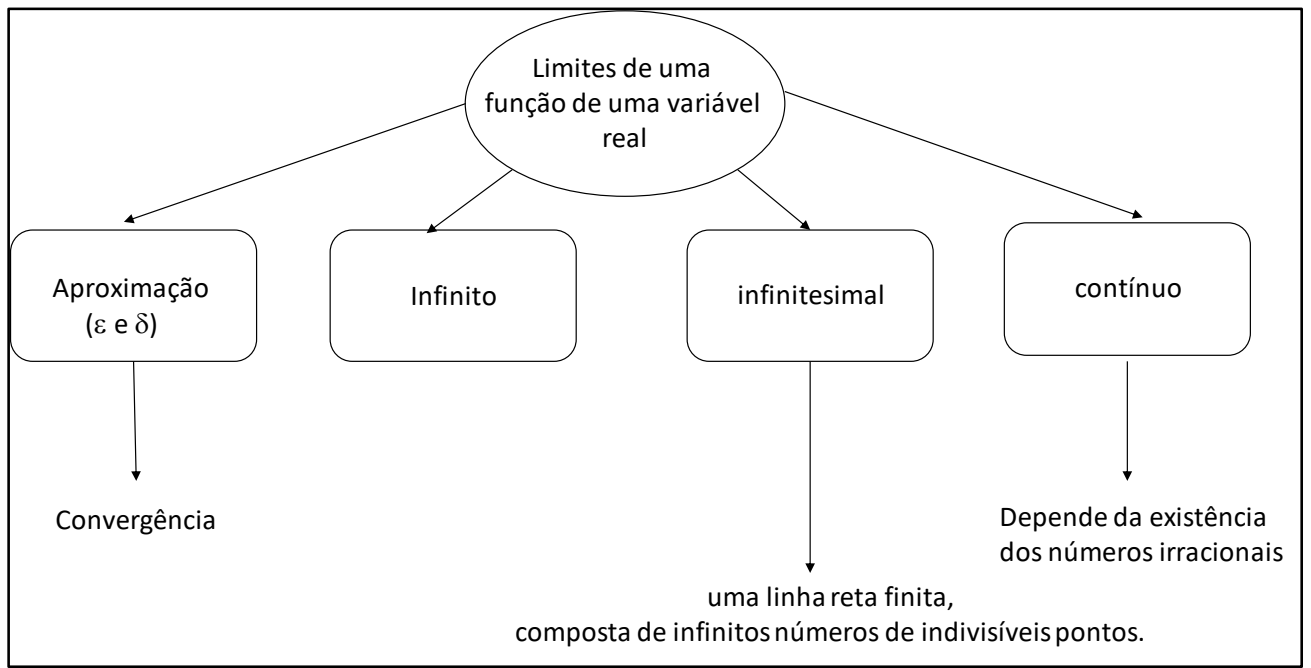

Figura 2: Ideias que envolvem o conceito de Limite

Tall (1980) constatou que os conflitos referentes a aspectos linguísticos da definição formal de limites se referem a falha no conceito de infinitesimais, pois ao conceituar limites 
temos que manipular grandezas infinitesimais e, o aluno precisa apropriar-se primeiramente deste conceito

Diante dos resultados de sua pesquisa, Zuchi (2005, p. 206) diz que:

Na observação realizada em classe identificaram-se várias dificuldades no processo de ensino aprendizagem do conceito de limite. Alguns desses obstáculos já tinham sido observados no contexto histórico, tal como a dificuldade de se trabalhar com grandezas infinitesimais e com a noção do infinito. Uma dificuldade bastante acentuada foi a relação entre epsilon e delta na definição de limite pelo ponto de vista de aproximação. Constatou-se que essa dificuldade de aprendizagem era gerada por vários fatores, dentre os quais pode-se destacar: o obstáculo da linguagem matemática, a falha em conteúdos básicos como funç̃es e inequações e principalmente, o obstáculo presente na passagem da noção intuitiva, a qual utiliza-se do ponto de vista cinemático, diretamente para a definição de limite pelo ponto de vista de aproximação, de uma maneira direta e formalizada.

Em relação as conclusões de sua pesquisa, Lira (2008, p. 114) afirma que:

O conceito de limite envolve muito mais que uma definição. Ele envolve mecanismos cognitivos, os quais nós exercitamos desde criança, tais como ordenar, seriar, encaixar, separar, recompor e realizar envolvimentos, ou seja, relações topológicas estudadas por Piaget junto a crianças. Para atingir tais mecanismos na formalização avançada é necessário construir o conceito de contínuo numérico, que necessita destas relações, mas realizadas de forma infinita. Existe ainda a necessidade da generalização destas relações e das operações envolvidas.

No relato histórico desta seção abordaremos o contexto em que essas ideias matemáticas, explicitadas na Figura 2, surgiram.

A matemática egípcia e babilônica era caracterizada pelo empirismo e, isso satisfazia as questões do cotidiano. Além disso, a classe sacerdotal era detentora do conhecimento, inclusive do conhecimento matemático. Eles eram os intermediários entre a divindade e o povo. Mas, a matemática grega não se sustentou com o empirismo e, nem com o domínio dos sacerdotes, principalmente devido a fixação de um povo nômade, os aqueus que se fixaram na Grécia e, trouxeram com eles uma nova cultura. Durante um tempo, os aqueus exerceram um certo domínio sobre os aspectos socioeconômicos da região. Segundo Burnet, "foi provavelmente devido aos aqueus que os gregos nunca tiveram uma classe sacerdotal, e isso pode bem ter tido algo a ver com o aparecimento da ciência livre entre eles" (BURNET, 1957, p. 4).

Mas, alguns filósofos antigos já questionavam sobre o mundo a sua volta, acerca de questões inseridas no contexto da cosmologia e, a partir daí também passaram a surgir questões divergentes entre a ciência e o senso comum. Do ponto de vista filosófico pode se dizer que o século $\vee$ a.C. foi caracterizado por essas questões e, a necessidade dos filósofos em defender os seus paradoxos contra os preceitos da visão não científica. Toda esta articulação do discurso retórico empregado deu origem a criação da Lógica, no sentido mais amplo do seu significado. (BICUDO, 1998)

Essa influência do pensamento filosófico da época levaram os matemáticos antigos a tentaram fazer uma analogia entre os pensamentos matemáticos e o mundo físico. Os 
filósofos procuravam explicar o que consideravam a verdade através da matemática. Uma das questões fundamentais da época era: "ou o tempo e o espaço são infinitamente divisíveis, isto é, divisíveis sem fim, ou existe um menor elemento indivisível de tempo (um instante) e de espaço (um ponto)" (BARON \& BOS, 1985, v.1, p.23). Essas questões surgiram a partir dos paradoxos de Zenão, paradoxos relativos ao movimento e ao tempo (ROQUE, 2012, p.134)

Estes paradoxos incluem um conjunto de problemas que criam dúvidas sobre o movimento. Existe algum movimento? E se sim, como? Nós chegamos ao nosso destino?

As discussões sobre os paradoxos de Zenão ocorreram por volta do século $V$ a.C. Zenão era um filósofo grego, da escola eleática, que tinha em Parmênides um de seus expoentes. A filosofia de Parmênides é conhecida por ter inspirado Platão e, sobretudo, por conceber o mundo como imutável, ou seja, não há movimento, não há mudança, não há nascimento, nem morte, não há espaço e nem tempo. Segundo, Bicudo (1998) os eleatas em primeiro lugar defendiam a unidade do espaço, que deveria ser indivisível, e a permanência do ser no tempo, que corresponde a ausência de mudança. Em segundo lugar, defendiam a acessibilidade do ser só ao pensamento racional e, a condenação do mundo sensível e do conhecimento sensível como aparência. Essa segunda característica é responsável, pela mudança da matemática empírica para a matemática teórica.

Zenão, seguidor de Parmênides se especializou em fazer perguntas aparentemente inocentes sobre o mundo físico que imediatamente causavam inúmeras discussões filosóficas. Na realidade, segundo Roque (2012, p. 133) na época os paradoxos de Zenão tinham mais um papel filosófico que alguma relevância para o desenvolvimento do cálculo e, especificamente para a noção de limite, mas é um fato que esses paradoxos causaram um certo impacto ao pensamento da época.

Segundo Radice (1981, p.44), Zenão de Eléia não queria demonstrar a impossibilidade do movimento, mas reduzir ao absurdo as teses dos pitagóricos, que compunham o contínuo com mônadas de dimensão finita. A Escola Pitagórica tinha assumido que o espaço e o tempo podem ser pensados como consistindo de pontos e instantes, mônadas, que para eles era o indivisível. Na concepção pitagórica de número está subjacente a ideia de atomismo numérico na qual a reta seria composta de unidades indivisíveis. Nesse caso, o espaço seria composto de pontos e o tempo de instantes.

Aristóteles (384-322 a.C.) tentou refutar os paradoxos de Zenão com argumentos filosóficos. Para ele era desnecessário usar a ideia do infinitamente pequeno, pois: "se adicionarmos continuamente a uma quantidade finita, excederemos qualquer grandeza dada e, do mesmo modo, se subtrairmos continuamente dela chegaremos a alguma coisa menor do que ela" BARON \& BOS, 1985, v.1, p.27).

Apesar da discordância entre a experiência sensível e a aparente força dos argumentos (GILES, 1979, p.40), o pensamento de Zenão de Eléia teve um resultado positivo, pois obrigou a uma revisão crítica de conceitos fundamentais, tais como: infinito, contínuo, número, tempo e movimento. Surgem as primeiras preocupações sobre como definir e interpretar o infinito, mesmo que do ponto de vista filosófico.

Para Struik (1997, p. 82), "os argumentos de Zenão começaram a preocupar ainda mais os matemáticos, depois de terem sido descobertos os irracionais". Logo, essa descoberta surgiu a partir de um problema geométrico, o problema de usar o lado para medir a diagonal de um quadrado. E, na época era usada a antifairese (ROQUE, 2012, p. 127) para mostrar que o lado e a diagonal do quadrado não são comensuráveis. 
Logo, neste pequeno relato do estágio inicial, percebe-se que as ideias da Figura 2 são enunciadas em seus respectivos contextos e, desenvolvimento do pensamento filosófico, que naquela época impulsionou a existência do rigor matemático, posteriormente com o surgimento da análise.

Dessa forma, pode-se dizer que os matemáticos e filósofos gregos da época contribuiram no levantamento de questões e, debates filosóficos sobre ideias que são fundamentais no desenvolvimento do conceito formal de Limites de uma Função de uma variável real. Logo, construiu-se uma parte do mapa epistemológico deste objeto matemático, no que se refere ao Estágio Inicial, Figura 3, o qual é validado a partir do esquema da Figura 2 e, das pesquisas enunciadas anteriormente.

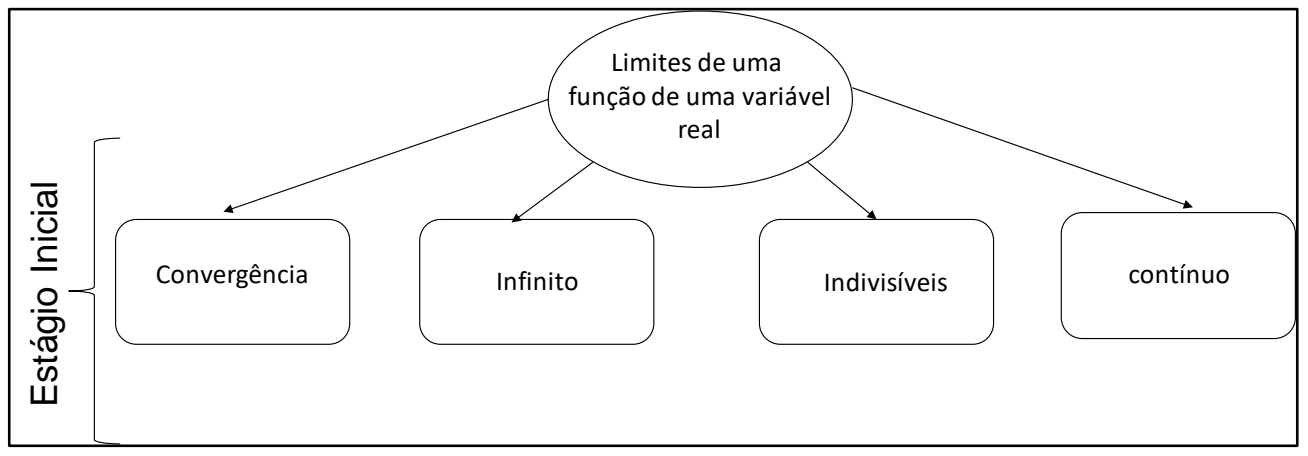

Figura 3: Mapa Epistemológico - Parte I

Além disso, no que diz respeito à dimensão epistemológica deste saber, concluiu-se que é imprescindível o conhecimento e interpretação de algumas dualidades:

i. dualidade finito/infinito: do ponto de vista histórico esta questão levou muito tempo para ser compreendida. $E$, pesquisas também relatam dificuldades inerentes desta falta de conhecimento (SIERPINSKA, 1985 apud ARTIGUE, 1990). Como por exemplo: o horror ao infinito, a partir de questões relacionadas à ideia de infinitamente pequeno, a questão no que se refere saber se o limite deve ou não deve ser alcançado. Outro fato em relação ao infinito diz respeito às "simplificações algébricas" que os alunos realizam no cálculo dos limites. Não reconhecem as situações de indeterminação presentes em cada um dos limites e procuram traduzir e resolver as indeterminações através de uma espécie de álgebra do infinito. O interessante é que o infinito passa a se comportar como número. Resultados como estes podem ser encontrados nas pesquisas de Sierpinska (1987).

ii. Dualidade discreto/contínuo: percebe-se esta dificuldade do ponto de vista histórico em algumas questões conflitantes sobre as reflexões acerca dos paradoxos de Zenão, como por exemplo, o espaço e o tempo são contínuos ou discretos? E, atualmente pesquisas relatam as implicações desta falta de conhecimento na construção do conceito de limites. (REZENDE, 2003)

iii. Dualidade divisíveis/ indivisíveis: para a análise de limites vimos que do ponto de vista histórico e do desenvolvimento deste conceito é fundamental o conhecimento de que o tempo e o espaço são divisíveis.

iv. Convergência/Divergência: são conhecimentos importantes, principalmente a ideia de que ao se somar uma infinidade de quantidades cada vez menores pode-se obter uma grandeza finita para esta soma, uma das dificuldades no Paradoxo de Áquiles e a 
Tartaruga. Implicitamente a este fato está a ideia de convergência de uma soma infinita.

\section{Estágio Intermediário}

Apesar dos gregos (400 - 300 a.C), por exemplo, já se depararem com questões que de certa forma envolviam o conceito intuitivo de limites, nem sequer pensavam sobre 0 conceito de limites, até porque era inadmissível naquele período.

A história se desenvolve conforme as necessidades da época, mas o que é certo é que todo e qualquer tipo de descoberta em matemática impacta diretamente no conhecimento a posteriori.

Do ponto de vista da análise, a questão "quando tender a infinito" é recente. Mas, problemas como o de calcular a área de um círculo, por exemplo, foi um marco que pode ser usado atualmente para se desenvolver a noção intuitiva deste conceito.

Uma das primeiras soluções desse tipo foi fornecida por Hipócrates de Chios. Ele provou que "a razão das áreas de dois círculos é igual à razão dos quadrados dos seus diâmetros" (EDWARDS, 1979, p.7). Ele conseguiu isso inscrevendo nos dois círculos, polígonos regulares semelhantes e, exaurindo as áreas dos círculos aumentando indefinidamente o número dos lados dos polígonos. Uma vez que em cada etapa, a razão dos dois polígonos inscritos é igual à razão dos quadrados dos diâmetros dos dois círculos, pareceria resultar "no limite" que o mesmo é verdade, levando-se em consideração as áreas dos círculos. No entanto, Hipócrates não tinha um conceito de limite capaz de terminar seu argumento.

A dificuldade de extensão deste método quando o número de lados aumenta indefinidamente só teria sido percebida por Eudoxo. Como Hipócrates acreditava no princípio da continuidade, não deve ter achado inconveniente utilizar o método de aproximação de áreas de círculos por áreas de polígonos com um número de lados crescendo indefinidamente. (ROQUE, 2012, p.156-158)

Mas, é com Eudoxo que surge a teoria das proporções entre quatro grandezas, exposta no livro $V$ de Euclides. Uma das motivações de Eudoxo pode ter sido aprimorar os procedimentos infinitos usados por Hipócrates em sua medida do círculo. O uso de processos que tendem ao infinito foi efetuado por Arquimedes, usando sequências de aproximações finitas da área do círculo por polígonos. (ROQUE, 2012, p.192-193)

O método de Eudoxo consistia em inscrever polígonos regulares em uma figura curvilínea, como um círculo e ir dobrando o número de lados até que a diferença entre a área da figura e a do polígono inscrito se tornasse menor do que qualquer quantidade dada. No século XVII este tipo de procedimento ficou conhecido como método da exaustão. O método se baseia no fato de que o infinito não pode ser levado à exaustão, isto é, não admite ser exaurido - pois por mais que nos aproximemos, nunca chegaremos até ele.

Esse método também ficou conhecido como "Postulado de Arquimedes", e pode ser considerado como uma resposta aos paradoxos de Zenão, Eves (2011, p.419) relata que dos antigos, quem aplicou de maneira mais elegante o método da exaustão foi Arquimedes (287-212 a.C) se aproximando da atual e verdadeira integração. A base da proposição do método é o seguinte:

Se de uma grandeza qualquer se subtrai uma parte não menor que sua metade, do restante subtrai-se também uma parte não menor que sua 
metade, e assim por diante, se chegará por fim a uma grandeza menor que qualquer outra predeterminada da mesma espécie. (EVES, 2011, p.419).

No entanto, apesar do fato de que o método de exaustão parece extremamente próximo da noção de limite, não podemos afirmar que os gregos possuíam o conceito de limite atual. O método de exaustão é, na essência, um método geométrico que permite a prova de resultados sem ter que lidar com o problema do infinito. É aplicado a magnitudes geométricas, não a números. Cada caso é tratado individualmente usando um argumento específico adaptado ao contexto geométrico. Não há transferência de figuras geométricas para uma interpretação puramente numérica, de modo que o conceito unificador de limite de números está ausente.

Arquimedes contribuiu para a noção de limite, pois ele usou um conceito relativo a limites: indivisíveis - quantidades infinitamente pequenas. Nas suas demonstrações rigorosas das fórmulas para certas áreas e volumes, ele encontrou várias séries infinitas e não possuindo o conceito de limite propriamente dito, inventou argumentos muito engenhosos chamados de "redução ao absurdo duplo", que, na verdade, incorporam alguns detalhes técnicos do que agora chamamos de limites (THOMAS, 2006).

Segundo Robertson e O'Connor (1996) nenhum progresso adicional foi feito até o século XVI, quando a mecânica começou a levar os matemáticos a examinar problemas como os centros de gravidade. Luca Valerio (1552-1618) publicou De quadratura parabolae em Roma (1606), que continuou os métodos gregos de atacar esses tipos de problemas de área. Kepler, em seu trabalho sobre o movimento planetário, teve que encontrar a área de setores de uma elipse. Seu método consistia em pensar em áreas como somas de retas, outra forma de integração, mas Kepler tinha pouco tempo para o rigor grego e teve sorte de obter a resposta correta depois de cometer dois erros de cancelamento neste trabalho.

Segundo Robertson e O'Connor (1996), Bonaventura Cavalieri em sua obra mais conhecida, Geometria indivisibilibus continuorum nova, desenvolveu a ideia de Kepler sobre quantidades infinitamente pequenas. Aparentemente, Cavalieri pensou na área como uma soma infinita de componentes ou segmentos "indivisíveis". Ele mostrou, usando os seus métodos, o que hoje em dia escrevemos: $\int_{0}^{a} x^{n} d x=\frac{a^{n+1}}{n+1}$

Outros, tais como Evangelista Torricelli, Pierre de Fermat, John Wallis e St. Vincent de Gregory, planejaram técnicas de quadratura e/ou de cubatura que se aplicavam a regiões ou a sólidos específicos. Mas nenhum deles usou limites. Os resultados estavam quase todos corretos, mas cada um dependia de uma argumentação não algébrica, recorrendo à intuição geométrica ou filosófica, questionável em algum ponto crítico. A necessidade para os limites era justa, mas não reconhecida.

Nesta seção nos deparamos sobre outro aspecto relacionado ao desenvolvimento da noção de limites: a visão geométrica intuitiva subjetiva e, não rigorosa.

O mapa epistemológico, Figura 4, mostra exatamente o que marcou este período, a visão geométrica grega. Logo, pode-se dizer que a fase denominada neste trabalho como intermediária apresentou as duas maiores contribuições de Eudoxo: a Teoria das Proporções e o Método de Exaustão como avanços do ponto de vista geométrico à solução de problemas relacionados à área e volume de diversas figuras geométricas. 


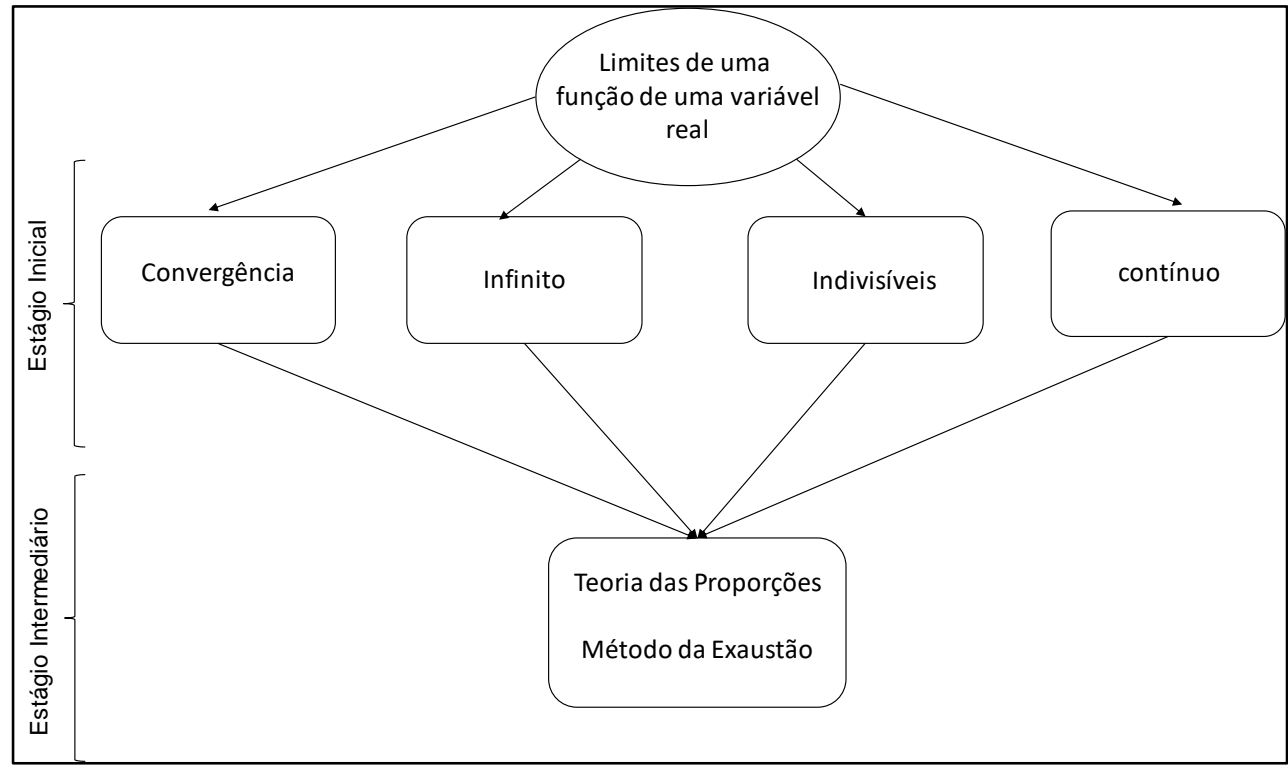

Figura 4: Mapa Epistemológico - Parte II

Segundo Brolezzi (1996, p. 27):

A diferença entre o método de exaustão e o limite do Cálculo Diferencial e Integral reside apenas no fato de os gregos não realizarem essa passagem ao infinito, pois não tinham noção de um continuum aritmético. Mas o tipo de argumentação é o mesmo, tanto no caso do atual limite quanto no método de exaustão geométrico. Pode-se talvez dizer que a noção de limite tivesse sido vislumbrada pelos gregos.

\section{Estágio Formal}

Este estágio é caracterizado pelo relato de contribuições de matemáticos que culminou na Aritmetização da Análise, a qual foi uma busca pela fundamentação do Cálculo não mais de maneira geométrica, mas sim por meio dos números.

Primeiramente começaremos com as contribuições de Isaac Barrow (1630-1677), o qual de acordo com Boyer e Merzbach (2012, p. 270), produziu contribuições significativas para o desenvolvimento posterior do Cálculo, em especial com a criação do método para determinação de tangentes a curvas, pelo uso do triângulo diferencial denominado também triângulo de Barrow.

No século XVII surgem os trabalhos de Isaac Newton (1642 - 1727) e Gottfried Wilhelm Leibniz (1646 - 1716). Brolezzi (1996, p. 30) compara os estilos de Newton e Leibniz, da seguinte forma:

Podemos dizer assim que, em termos de tendência, ou estilo, Newton teria chegado ao Cálculo pela via do contínuo, e Leibniz, pela via do discreto. Ambas as maneiras de abordar o problema mostraram-se igualmente úteis, pois, enquanto não estava estabelecida a noção de limites, as ideias de movimento contínuo e de infinitésimos discretos surgiram como tentativas de esquematizar as impressões sensíveis a respeito da variação.

Isaac Newton contribuiu de forma relevante para o aparecimento da teoria dos limites, em Principia Mathematica, seu maior trabalho em Matemática e Ciência. No começo do 
livro I do Principia, tentou dar uma formulação precisa para o conceito do limite. Ele havia descoberto o papel preliminar que o limite teria no Cálculo, sendo essa a semente da definição moderna:

Quantidades, e as razões de quantidades, que em qualquer tempo finito convergem continuamente para à igualdade, e antes do fim desse tempo se aproximam mais uma da outra que por qualquer diferença dada se tornam finalmente iguais. (BOYER e MERZBACH, 2012, p.275).

Após a difusão das ideias relativas ao Cálculo proposto por Newton e por Leibniz, houveram muitas críticas, um dos primeiros críticos foi George Berkeley (1685-1753), questionando que os princípios utilizados necessitavam de maior clareza e segurança. Bertato e D'Ottaviano (2009) complementam que, Berkeley ataca fortemente a lógica do método das fluxões.

Segundo Brolezzi (1996, p.30), Newton se referia a seu Cálculo como o "Método das Fluxões", sendo a fluxão uma velocidade finita, e não uma quantidade infinitamente pequena. As variáveis eram consideradas como quantidades fluentes. Os conceitos mecânicos e cinemáticos eram usados como variáveis, o que equivale a considerá-las funções do tempo. Para Newton, o conceito fundamental do Cálculo é eminentemente cinemático e a ideia central é a de fluxão $x$, vetor velocidade de $x$, ou taxa de mudança da variável. "Trata-se da decomposição no eixo x do vetor velocidade do ponto."

Segundo Bertato e D’Ottaviano (2009), Berkeley argumenta que o infinitésimo de Newton era contraditório, pois inicialmente o tratava como uma grandeza finita e, em um estágio posterior, como zero, conforme sua conveniência. Essa controvérsia de Berkeley e Newton sobre o método das fluxões adquiriu uma grande magnitude, fazendo alguns matemáticos a se posicionarem a respeito dele. Nessas discussões, foi sugerido o conceito de limite como solução para os problemas levantados. Um dos primeiros a se posicionar foi Benjamin Robins (1707-1751), dando a seguinte explicação sobre o que entendia por limite: "...nós... definimos uma grandeza última como sendo o limite do qual uma grandeza variável pode aproximar-se em qualquer grau de proximidade, embora ela nunca possa tornar-se absolutamente igual a ele" (BARON \& BOS, 1985, v.3, p.27).

Outro importante matemático que se manifestou foi Jean Le Rond D'Alembert (17171783), que defendeu o uso da teoria dos limites para fundamentar as bases do Cálculo. Ele explicou o conceito de limite da seguinte forma:

Diz-se que uma grandeza é o limite de outra grandeza quando a segunda pode aproximar-se da primeira tanto quanto se queira, embora a primeira grandeza nunca possa exceder a grandeza da qual ela se aproxima; de modo que a diferença entre tal quantidade e seu limite é absolutamente indeterminável (BARON \& BOS, 1985, v.3, p. 28).

Após essa definição feita por d'Alembert, o conceito de limite foi, durante cerca de mais de meio século, uma das maneiras de acertar os fundamentos do Cálculo. Porém, esta não foi aceita como solução, já que necessitava de maior clareza no conceito de variável (BARON \& BOS, 1985, v.3).

O desenvolvimento do cálculo para a análise envolveu uma transformação da natureza da matemática desenvolvida até então, conforme relata Baron \& Bos (1985):

O cálculo por volta de 1700 era ainda essencialmente orientado para a geometria. Tratava de problemas sobre curvas, empregava símbolos 
algébricos, mas as quantidades que se utilizava eram principalmente interpretadas como ordenadas e abscissas de curvas, ou como outros elementos de figuras geométricas. Durante a primeira metade do século diminuiu o interesse pela origem geométrica dos problemas, e os matemáticos passaram a se interessar mais pelos símbolos e fórmulas do que pelas figuras. A análise tornou-se o estudo e manipulação de fórmulas. (BARON \& BOS, 1985, p. 43, v.3)

E, esta mudança estava associada ao surgimento do conceito de função.

Em 1784, a Academia de Ciências de Berlim ofereceu um prêmio para quem explicasse com sucesso uma teoria do infinito pequeno e do infinito grande na matemática e que pudesse ser usado no Cálculo como um fundamento lógico e consistente. Embora esse prêmio tenha sido ganho por Simon L'Huilier (1750 - 1840) pelo seu trabalho "longo e tedioso", este não foi considerado uma solução para os problemas propostos. Lazare N. M. Carnot (1753 - 1823) propôs uma tentativa popular de explicar o papel do limite no Cálculo como "a compensação dos erros", mas não explicou como estes erros se balançariam sempre perfeitamente.

Jean Baptiste Joseph Fourier (1768-1830) em sua teoria do calor tentou definir a convergência de uma série infinita, porém, sem usar limites, então ele afirmou que qualquer função poderia ser escrita como uma de suas séries, e não mencionou a convergência ou divergência dessa série.

Mas, no século XIX, Augustin Louis Cauchy (1789-1857) foi o primeiro a defender e divulgar a nova forma rigorosa de se fazer matemática que invadiu quase toda a análise. Iniciava-se o processo de aritmetização da análise. Ele procurava por uma exposição clara e rigorosamente correta do Cálculo para apresentar aos seus estudantes de engenharia na École polytechnique em Paris (THOMAS, 2006) e, com base no conceito de limite de d'Alembert, ele conseguiu dar uma definição mais clara de limite, tal que as noções de discreto e contínuo pudessem ser trabalhadas:

Chamamos quantidade variável aquela que consideramos capaz de assumir diversos valores diferentes sucessivamente. Por outro lado, chamamos quantidade constante aquela que assume um valor fixo e determinado. Quando os valores sucessivamente atribuídos a uma variável se aproximam indefinidamente de um valor fixo, de modo que eles finalmente difiram deste valor tão pouco quanto quisermos, esse último valor é chamado limite de todos os outros. Assim, por exemplo, a área do círculo é o limite para o qual convergem as áreas de todos os polígonos regulares inscritos, se o número de seus lados aumentar cada vez mais (...) indicaremos o limite para o qual converge determinada variável pela abreviação "lim" escrita antes da variável em questão. (BARON \& BOS, 1985, v.3, p. 46).

A diferença da definição de limite proposto por Robins e d'Alembert com relação à de Cauchy reside no fato de Cauchy não excluir a possibilidade de a variável alcançar seu limite. Contudo, Thomas (2006) comenta que ele perdeu alguns dos detalhes técnicos, especialmente na aplicação da sua definição de limite a funções contínuas e à convergência de certas séries infinitas.

A construção, fundamentação e consolidação do cálculo diferencial e integral só seria possível com uma constituição rigorosa de número real, e isto só ocorre na segunda 
metade do século XIX, com as contribuições de Carl Friedrich Gauss (1777-1855), Georg Cantor (1845-1918), Augustin Louis Cauchy, Richard Dedekind (1831-1916) e Karl Weirstrass (1815-1897) (ZUCHI, 2005).

Então, com a noção de limite estabelecida por Cauchy, Weierstrass formaliza o Cálculo utilizando a linguagem de epsilons e deltas propondo a seguinte definição:

O número $L$ é o limite da função $f(x)$, onde $x=x_{0}$ se, dado qualquer número arbitrariamente pequeno $\varepsilon$, outro número $\delta$ possa ser encontrado tal que para todos os valores de $x$ diferindo de $x_{0}$ por menos que $\delta$, o valor de $f(x)$ diferir de $L$ por menos que $\varepsilon$. (BOYER, 1959, p. 287, tradução nossa).

Esta definição é muito similar a definição atual dos livros de Cálculo Diferencial e Integral.

A partir deste relato, construiu-se o mapa epistemológico (Figura 5), atribuindo à formalização do conceito de Limites de uma função de uma variável real às primeiras ideias a respeito de convergência, infinito, indivisíveis e contínuo, as quais estavam presentes em problemas que envolveram a necessidade da Teoria das Proporções e o Método de Exaustão e, que com o processo da Aritmetização da Análise foi possível chegar à formalização presente na definição atual de Limites.

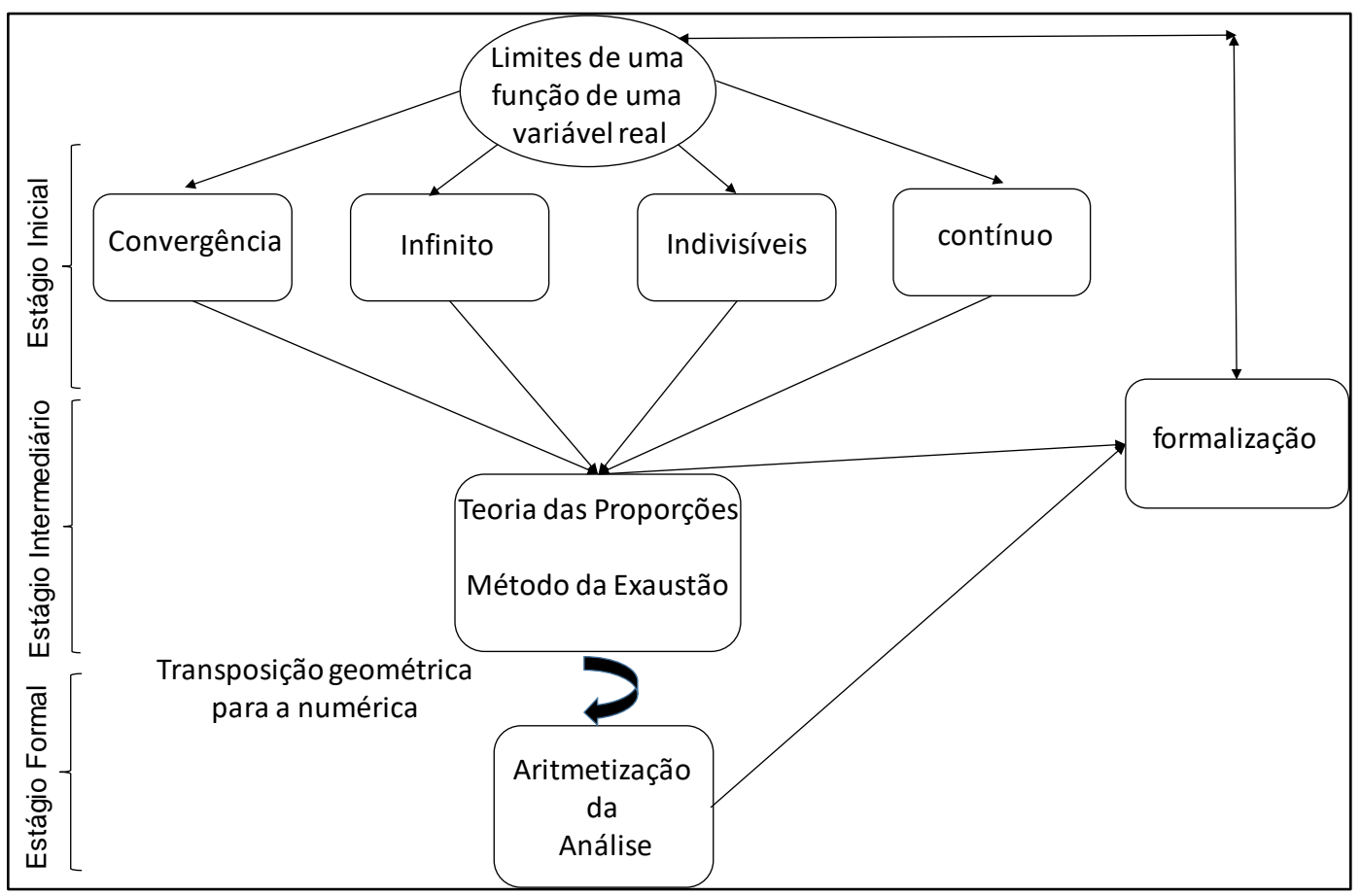

Figura 5: Mapa Epistemológico - Parte III

\section{Considerações Finais}

As análises dos estágios Intuitivo, Intermediário e Formal forneceu subsídios para responder as questões referentes a dimensão epistemológica do saber, as quais estão esquematizadas na Figura 6. 
A partir das análises realizadas nos estágios Inicial, Intermediário e Formal chegouse à conclusão de que a gênese do saber (Limites) está associada ao limite de razões incrementais.

Na Grécia do ponto de vista geométrico, os geômetras da época precisavam do saber Limites para estabelecer razões entre as grandezas, mas como não tinham este conhecimento e, nem sequer o imaginavam, recorreram a outras fontes, muitas vezes consideradas sem o devido rigor matemático e, geralmente criticadas na época.

Newton em seu trabalho Principia Mathematica reconheceu a necessidade deste Saber (Limites), no sentido geral de estabelecer limites de razões incrementais associados a vários tipos de problemas como os de tangência, problema investigado na época, quadratura e afins. Este trabalho foi o marco do reconhecimento e necessidade do Saber (Limites), além de ser o precursor de investigações no sentido de defini-lo.

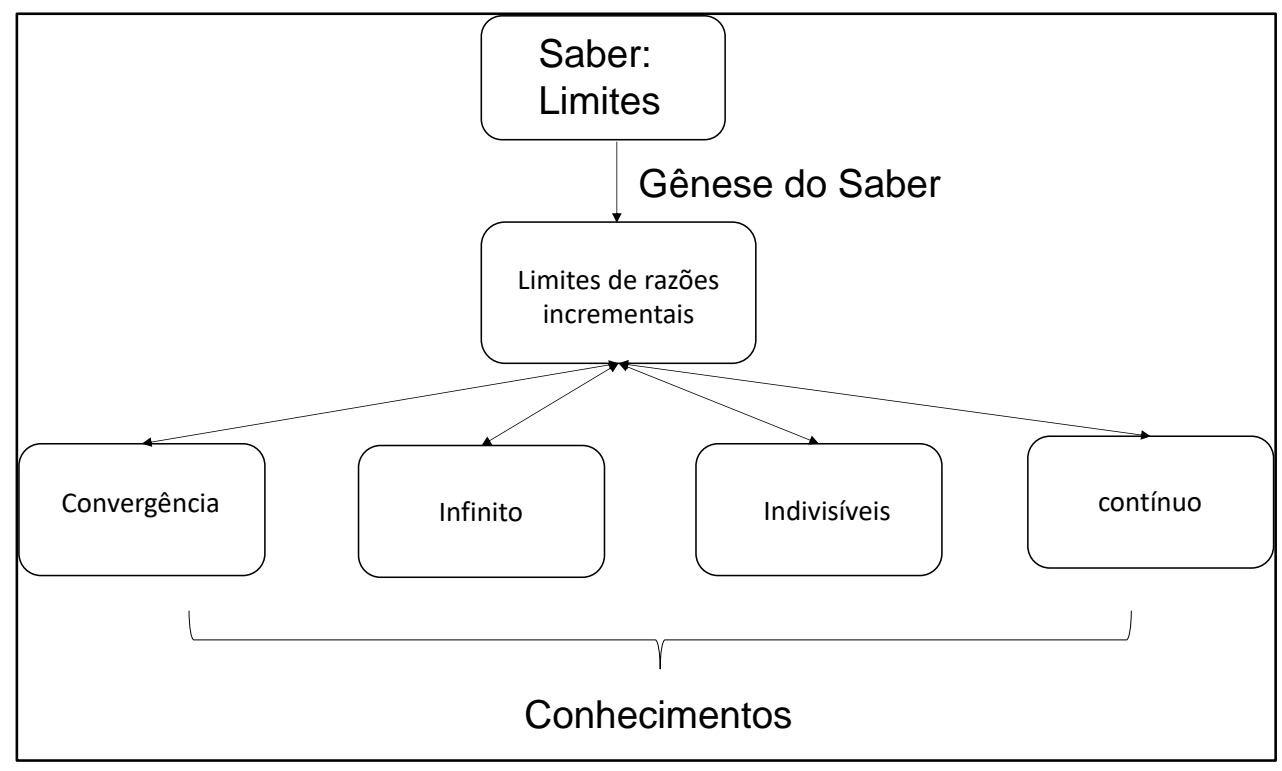

Figura 6: Dimensão Epistemológica do saber

Logo, para isso era essencial ter os conhecimentos que foram resultados de muitos debates do ponto de vista histórico e filosófico e, os quais estavam presentes nas definições de Limites de Newton, D'Alembert, Cauchy e Weierstrass presentes neste trabalho. Ou seja, conhecimentos sobre convergência, infinito (grandezas infinitesimais), indivisíveis e contínuo (noções de contínuo e discreto), para a partir destes conhecimentos outros conhecimentos serem adquiridos como noções de vizinhança e ponto de acumulação, definições consideradas recentes no contexto da análise matemática. Mas, tudo isso foi possível a partir da Aritmetização da Análise.

Deste trabalho de investigação e pesquisa conclui-se a importância e relevância de fatos históricos e epistemológicos do saber e, a influência destes no trabalho do pesquisador em didática da matemática e professor de matemática, no sentido de ampliar o conhecimento em relação aos fundamentos do saber e, os conhecimentos fundamentais relacionados, a partir dos quais a aprendizagem possa ser de fato significativa. 


\section{Referências}

ARTIGUE, M. Epistémologie et Didactique. Recherches en Didactique de Mathématiques.

França, vol 10, n²3, p. 241-286, 1990.

BARON, Margaret. E; BOS, H. J. M. Curso de história da matemática: origens e desenvolvimento do cálculo. vol 1-5. Trad. de José Raimundo Braga Coelho. Brasília: Editora Universidade de Brasília, 1985.

BERTATO, Fábio Maia; D’OTTAVIANO, Itala M. Loffredo. George Berkeley e os Fundamentos do Cálculo Diferencial e Integral. Seminários Filosóficos em Engenharia, Ciências e Áreas Afins. Unicamp, 2009. Disponível em < ftp://ftp.cle.unicamp.br/pub/Thematic-LogConsFAPESP/Report-02-2012/Papers/[DB12].pdf>. Acesso em 21 de abril de 2018.

BICUDO, I. Platão e a Matemática. LETRAS CLÁSSICAS, n. 2, p. 301-315, 1998.

BOYER, Carl Benjamin. The history of the calculus and its conceptual development. New York: Dover, 1959.

BOYER, Carl Benjamin; MERZBACH, U.C.. História da matemática. 3. ed. São Paulo: Edgard Blucher, 2012.

BROLEZZI, A. C. A Tensão entre o Discreto e o Contínuo na História da Matemática e no Ensino de Matemática. Tese de Doutorado. Faculdade de Educação. Universidade de São Paulo, 1996.

BURNET, J. Early Greek Philosophy. New York: Meridian Books, 1957.

D'AMBROSIO, U. Priorizar História e Filosofia da Matemática na Educação. XIII CIAEMIACME, Recife, Brasil, 2011.

EDWARDS, C. H. The Historical Development of the Calculus. New York, NY: SpringerVerlag, 1979.

EVES, Howard. Introdução à história da matemática. Tradução de Higino H. Domingues. 5. ed. Campinas: Unicamp, 2011.

GILES, Thomas Ransom. Introdução à Filosofia. São Paulo: EPU: Editora da Universidade de São Paulo, 1979.

LIRA, A. F. O processo da construção do conceito matemático de limite pelo aprendiz com a utilização de objetos digitais. Tese de Doutorado. Programa de Pós-graduação em Informática na Educação. Universidade Federal do Rio Grande do Sul, 2008.

RADICE, Lucio Lombardo. O Infinito: De Pitagóras a Cantor itinerários filosóficos e matemáticos de um conceito de base. Lisboa: Editorial Notícias-Biblioteca de Conhecimentos Básicos, 1981.

REZENDE, W.M. O ensino de cálculo: dificuldades de natureza epistemológica. Dissertação de Mestrado. Universidade de São Paulo, 2003.

Robertson, E.F.; O'Connor, J.J. A history of the calculus, 1996. Disponível em: http://wwwhistory.mcs.st-andrews.ac.uk/HistTopics/The_rise_of_calculus.html. Acesso em 20 de abril de 2018 
ROQUE, T. História da Matemática - Uma visão crítica, desfazendo mitos e lendas Rio de Janeiro: Jorge Zahar, 2012.

SIERPINSKA, A. Humanities Students and Epistemological Obstacles Related to Limits. Educational Studies in Mathematics, 18, 1987.

STRUIK, Dirk. História concisa das Matemáticas. (3a edição). Lisboa: Gradiva. 1997

TALL, David. Intuitive infinitesimals in the calculus - Poster presented at the Fourth International Congress on Mathematical Education, Berkeley, 1980, with abstract appearing in Abstracts of short communications, page C5.

THOMAS, George Brinton. Calculus Biographies, 2006. Disponível em: http://kisi.deu.edu.tr/engin.mermut/mat1025_10g_dosyalar/CalculusBiographiesThomasCalculus.pdf. Acesso em 21 de abril de 2018.

ZUCHI I. A abordagem do conceito de limite via sequência didática: do ambiente lápis papel ao ambiente computacional. Tese (Doutorado) - Programa de Pós-Graduação em Engenharia de Produção, UFSC, Florianópolis, 2005. 